\title{
Kajian Biofisik Lahan Untuk Tanaman Porang Sebagai Anasir Konservasi Pada Sistem Agroforestri Di Pulau Lombok
}

\section{Study Of Land Biophysical For "Porang" (Amorphopallus Muelleri) As A Conservation Aspect In Agroforestry System In Lombok Island}

\author{
IGM Kusnarta*, Mahrup, Padusung, I Nym Soemeinaboedhy, Fahrudin \\ Jurusan Ilmu Tanah Fakultas Pertanian Universitas Mataram \\ *Corresponding Author Email: igm_kusnarta@yahoo.com
}

Manuscript received: 08-12-2020. Accepted: 26-10-2021

\begin{abstract}
ABSTRAK
Lahan pertanian di Lombok Utara didominasi oleh tipologi lahan sub optimal, baik secara fisik, kimia maupun biologi. Sifat tersebut menjadikannya rentan terhadap degradasi. Pada lahan yang demikian ini, dianjurkan sistem pertanian wanatani atau agroforestri, dimana tanaman porang dapat disertakan sebagai salah satu komponen. Tanaman porang mulai popular sebagai komoditas bernilai ekonomi, dan cocok sebagai tanaman sela. Sifatnya yang mudah tumbuh pada hampir semua jenis tanah, serta tahan terhadap naungan, menjadikannya adaptif pada sistem agroforestri sebagai tanaman non kayu di bawah tegakan pada sistem hutan kemasyarakatan. Hal ini diyakini akan memberi manfaat ganda, yaitu manfaat ekonomi dan lingkungan, jika disertai kaidah konservasi tanah dan air. Peran porang sebagai agen konservatif telah diteliti melului pendekatan ilmiah sebagai dasar dalam domistikasi tanaman porang dalam sistem agroforestri. Hasil penelitian menunjukkan, bahwa tanaman porang dapat membantu meningkatkan stabilitas dan kemantapan agregat tanah yang ditunjukkan oleh indeks kemantapan agregat tanah 59 yang berarti "agak mantap". Lengasan tanah kering angin pada areal tanaman porang meningkat dari 3.0\% (tanpa porang) menjadi 5.4\% (dengan keberadaan porang). Selain itu, kandungan bahan organik tanah meningkat menjadi 3,94\% (cukup tinggi) pada lahan yang ditanami porang disebabkan karena batang dan daun tanaman porang cepat melapuk. Penutupan permukaan tanah relative rapat, sehingga dapat mencegah erosi. Tanaman porang berperan meningkatkan penyerapan air (infiltrasi) karena keberadaan perakaran dan umbi porang. Dengan demikian domistikasi porang memenuhi syarat sebagai tanaman non kayu pada sistem agroforestri bila dibuddidayakan sesuai prinsip konservasi tanah dan air pada tipologi lahan sub optimal di Lombok Utara.
\end{abstract}

Kata kunci: degradasi; erosi; agroforestri; porang; pertanian lestari

\begin{abstract}
Agricultural land in North Lombok is dominated by a typology of sub-optimal land, physically, chemically and biologically. These properties make it vulnerable to degradation. In such land, agroforestry system is highly recommended, where the porang plant can be included as a component. Nowdays, porang is gaining popularity as a commodity with economic value, and is suitable as an intercropping plant. It is easy to grow on almost all types of soil, and is resistant to shade, making it adaptive to agroforestry systems as non-timber under standing plants in community forest systems. It
\end{abstract}


is believed that this will provide multiple benefits economicly and environmentaly, if it accompanied by the principles of soil and water conservation. The role of porang as a conservative agent has been investigated through a scientific approach as the basis for the domistication of porang in agroforestry systems. The results showed that agroforestry with porang could help improve the stability of the soil aggregates as indicated by the soil aggregate stability index 59 which means rather stable. Soil moisture of wilting point in agroforestry system with porang increased from $3.0 \%$ (without porang) to $5.4 \%$. In addition, the soil organic matter content increased to $3.94 \%$ (quite high) on the system with porang because the stems and leaves of porang plant are quickly weathered. The ground cover is relatively tight, so it can prevent soil erosion. Porang also play a role in increasing water infiltration due to the presence of porang's roots and tubers. Thus the domistication of porang fulfills the requirements as an agent of soil conservation, as non-timber plant in the agroforestry system, if it is cultivated according to the principles of soil and water conservation on the typology of sub-optimal land in North Lombok.

Keyword: Degradation; erosion; agroforestry; porang; sustainable agriculture

\section{PENDAHULUAN}

Lahan pertanian di Lombok sangat bervariasi, sesuai dengan kondisi biofisik lahan yang melingkupinya. Secara fisik karakteristik tanah bervariasi secara spasial; di bagian utara, bertekstur pasiran, struktur lepas, serta kedalaman solum relatif dangkal (Priyono et al., 2019), di bagian selatan bersifat sebaliknya, bertekstur klei (clay) didominasi oleh mineral montmorilonit yang memiliki sifat kembang-kerut sangat tegas (Kusnarta et al., 2011), dan berstruktur pejal (massive), dan solum tanahnya dalam (tebal) Secara kimia kedua jenis tanah tersebut memiliki kemiripan: kandungan C-organik tanah sangat rendah $(<1 \%)$, kandungan hara N, P, dan K rendah, serta kapasitas tukar kation (KTK), terutama untuk tanah di Lombok Utara rendah, yaitu $<5$ cmol.kg- (Priyono et al, 2019; Kusnarta et al., 2011). Semua karakter tanah tersebut mengarah pada sifat lahan sub optimal yang rentan terhadap degradasi kesuburan fisik, kimia maupun biologi tanah.

Lahan di kawasan Lombok Utara tersebut ternyata memiliki toleransi terhadap sistem pertanian wanatani atau agroforestri. Sistem agroforestri diyakini sebagai salah satu solusi untuk mengatasi kerentanan tanah dan lahan terhadap proses degradasi. Keutamaan sistem tersebut terletak pada penggabungan tanaman tahunan atau tanaman hutan/pohon dan tanaman pertanian atau tanaman semusim. Pada lahan yang tanahnya memiliki kesuburan rendah dan sensitif terhadap erosi, ternyata terkonvensasi oleh keberadaan tanaman yang selalu ada sepanjang waktu, sehingga sistem wanatani (Agroforestri) dapat memberi manfaat jangka panjang sebagai sebuah model pertanian konservasi (conservation agriculture). Hal ini dimungkinkan karena dalam sistem wanatani (Suprayogo et al., 2003) dapat tercipta daur karbon dan daur hara secara internal dan alami sehingga dalam jangka panjang lahan megalami penyehatan secara berangsur-angsur. Di samping itu, pengkayaaan bahan organik tanah, peningkatan kemantapan agregat tanah, dan akhirnya produktivitas tanah dapat meningkat, dan berkelanjutan.

Salah satu tanaman yang sedang memasuki fase popularitasnya adalah tanaman porong (Amorphophallus spp.) yang merupakan salah satu jenis tanaman etnobotani yang memiliki sejarah panjang dalam kehidupan masyarakat petani di Lombok. Umbi porong adalah pangan fungsional bagi masyarakat tani di lahan kering pulau Lombok. Tanaman ini hidup tanpa 
pengelolaan pada kawasan di sekitar hutan, ataupun pada kebun tradisional. Pada awalnya porang tidak dianggap memiliki potensi secara ekonomi. Domestikasi tanaman porong ke dalam sistem agroforestri dimungkinkan karena beberapa hal: (1) Porang dapat tumbuh hampir di semua jenis tanah, dengan rentang tempat tumbuh (berdasarkan tinggi tempat) dari dataran rendah hingga $1000 \mathrm{~m}$ dpl (Lahiya, 1993); (2) Porang tahan terhadap naungan dan dapat berproduksi atau menghasilkan umbi dengan baik meski tumbuh di bawah tegakan tanaman hutan (pohon) dengan tingkat naungan $>50 \%$ (Jansen et al., 1996); (3) Porang dapat dibudidayakan selama beberapa tahun (3-5 tahun) sebelum umbinya dipanen (Heyne, 1987); (4) Secara ekonomis porang sangat menjanjikan karena merupakan komoditas export dengan nilai harga tinggi; (5) Umbi porang memiliki banyak manfaat, yaitu sebagai bahan baku industri, bahan makanan, hingga bahan baku obat-obatan (Rosman dan Rusli, 1991).

Kandungan glukomanan yang tinggi pada karbohidrat umbi porang menjadikannya memiliki potensi sebagai bahan yang dapat menyerap air dengan baik. Dari aspek konservasi kondisi ini dapat meningkatkan kapasitas infiltrasi, sehingga dapat menurunkan laju limpasan permukaan. Akan tetapi, seberapa besar peran tanaman porang tersebut sebagai agen konservatif pada tipologi lahan pertanian di Lombok belum ada laporan. Untuk itu maka penelitian ini akan mengkaji peran tanaman porang dalam konservasi tanah dan air pada tipologi lahan di Lombok.

\section{Metode Penelitian}

\section{BAHAN DAN METODE}

Metode yang akan digunakan dalam penelitian ini adalah metode Deskriptif melalui tehnik survai dengan pendekatan kualitatif. Penelitian deskriptif kualitatif bertujuan untuk mengetahui kondisi biofisik dan peran tanaman porang yang ditanam diantara tegakan pohon (kayu/hutan) di wilayah pengembangan porang di Lombok Utara.

\section{Teknik Pengumpulan Data}

Penelitian ini akan menggunakan data primer, dengan cara survei atau observasi langsung di lapangan. Lokasi yang akan dijadikan sebagai tempat pengamatan adalah daerah sentra penanaman porang pada sistem agroforestri. Lokasi pengamatan ditetapkan secara purposive (dipilih) terhadap tempat-tempat yang merupakan sentra pengembangan porang. Contoh tanah akan diuji sifat fisiknya secara in situ (setempat), dan contoh tanah utuh akan diambil untuk dianalisis beberapa sifat fisiknya di laboratorium. Dengan demikian, akan dapat diketahui/diperoleh informasi tentang syarat biofisik tanaman porang pada sistem agroforestri. Jenis data yang digunakan dalam penelitian ini disajikan dalam Tabel 1.

\section{Data primer}

Data-data primer yang akan dihasilkan diperoleh dari pengukuran langsung di lapangan maupun di Laboratorium Fisika Tanah Fakultas Pertanian Universitas Mataram. Selengkapnya data tersebut disajikan pada Tabel 1. 
Tabel 1. Jenis data primer yang akan diukur di lapangan maupun di laboratorium

\begin{tabular}{cccc}
\hline No & Nama Data & Jenis Data & Sumber \\
\hline 1 & Kemiringan lahan (\%) & Primer & Pengukuran lapangan \\
2 & Kedalaman jelajah akar dan umbi & Primer & Pengukuran lapangan \\
3 & Tekstur tanah (pasir, debu, klei - \%) & Primer & $\begin{array}{c}\text { Lapangan dan Pengukuran } \\
\text { laboratorium }\end{array}$ \\
4 & Permeabilitas (cm/hari) & Primer & Pengukuran laboratorium \\
5 & Fenomena fisik akibat aktivitas & Primer & Pengamatan di lapangan \\
6 & manusia & primer & Lapangan dan Laboratorium \\
7 & Keteguhan tanah & primer & Lapangan \\
8 & Pencandraan profil tanah & primer & Lapangan/ laboratorium \\
\hline
\end{tabular}

\section{Data Skunder}

Data-data skunder yang akan dikumpulkan berupa: data curah hujan, jenis batuan, jenis tanah, penggunaan lahan dan data-data pendukung lainnya diperoleh dari beberapa instansi terkait (BPDAS, BWS NTB, BAPPEDA, BPBD, ESDM, Dinas PU dan kelompok masyarakat petani).

Pengumpulan data sekunder terdiri dari survei instansi dan survey literatur. Survei instansi merupakan survei yang dilakukan dalam mengumpulkan data sekunder atau pendukung di instansi atau dinas-dinas. Studi literatur atau kepustakaan dilakukan dengan meninjau isi dari literatur yang bersangkutan dengan tema penelitian ini, di antaranya berupa buku, hasil penelitian, dokumen rencana tata ruang, tugas akhir, serta artikel di internet dan media massa.

\section{Sampel Tanah dan Parameter Pengamatan Sampel tanah}

Sampel atau contoh tanah akan diambil secara komposit pada kedalaman $20 \mathrm{~cm}$ dari permukaan tanah. Titik tempat pengambilan sampel tanah tersebut akan ditetapkan menurut metode diagonal, untuk mendapatkan pewakil yang representatif. Pengambilan sampel tanah ini akan dilakukan dengan menggunakan bor tanah untuk contoh tanah terusik, sedangkan untuk contoh tanah utuh (unditurb soil sample) akan diambil menggunakan ring sampel dengan bantuan ring sampel, palu, dan pisau lapangan. Jumlah masing-masing contoh tanah tersebut adalah $0,5 \mathrm{~kg}$, sehingga pada setiap titik pengambilan akan berjumlah $1 \mathrm{~kg}$ tanah. Semua bentuk contoh tanah tersebut akan dikemas dalam kemasan plastik, agar kadar air atau kelembabannya dapat dipertahankan sebelum tiba di Laboratorium untuk kepentingan analisis.

\section{Parameter Pengamatan}

Parameter yang akan diamati dalam percobaan ini meliputi:

1. Kemantapan agregat tanah

2. Kadar klei ditetapkan melalui langkah-langkah pada analisis tekstur tanah

3. Kadar bahan organik tanah (B.O.)

4. Nilai BV (berat volume) tanah, 
5. Niali BJ (berat jenis atau berat partikel) tanah, dan

6. Nilai Porositas tanah, dan

7. Permeabilitas tanah

8. Kemantapan agregat tanah.

Kemantapan agregat tanah ditetapkan menggunakan metode pengayakan kering dan basah (De Leenheer and De Boodt, 1959 dalam Kertonegoro et al., 1998). Dengan metode ini dapat diperoleh perbedaan rata-rata berat diameter agregat tanah pada pengayakan kering dan pengayakan basah. Kadar klei ditetapkan melalui penetapan tekstur tanah dengan metode pipet (Gee dan Bauder, 1986). Porositas atau pengudaraan tanah dihitung setelah diperoleh nilai berat volume (BV) (Blake dan Hartge, 1986) dan berat jenis (BJ) tanah (Blake, 1986). Kadar bahan organik tanah ditetapkan menggunakan metode Walkley and Black (Nelson dan Sommers, 1982). Permeabilitas tanah berdasarkan hukum Darcy, dengan pendekatan rumus sbb:

$$
\mathrm{K}=\mathrm{Q} . \mathrm{L} / \mathrm{t} \cdot \mathrm{h} . \mathrm{A}
$$

Keterangan:

$$
\begin{aligned}
\mathrm{K} & =\text { Permeabilitas }(\mathrm{cm} / \mathrm{jam}) \\
\mathrm{Q} & =\text { Jumlah air yang keluar selama pengukuran }(\mathrm{ml}) \\
\mathrm{L} & =\text { Tebal contoh tanah }(\mathrm{cm}) \\
\mathrm{h} & =\text { Tinggi permukaan air dari permukaan tanah }(\mathrm{cm}) \\
\mathrm{t} & =\text { Waktu pengukuran }(\mathrm{jam}) \\
\mathrm{A} & =\text { Luas permukaan contoh tanah }\left(\mathrm{cm}^{2}\right)
\end{aligned}
$$

\section{Tempat dan Waktu Percobaan}

Percobaan akan dilaksanakan di lapangan dan di Laboratorium Fisika dan Kimia Tanah Fakultas Pertanian Universitas Mataram. Lokasi di lapangan akan ditetapkan daerah di mana terdapat penanaman porang di antara tegakan pohon. Semua lokasi penanaman porang tersebut memiliki kemiringan lahan yang relative seragam. Sebagai pembanding, juga akan diambil lokasi dimana tidak terdapat budidaya porang. Data tersebut akan dijadikan sebagai kontrol. Percobaan akan dilaksanakan selama 8 bulan, sejak bulan Maret 2020 hingga Nopember 2020.

Tabel 2. Rekam Jejak Penelitian (Road Map)

\begin{tabular}{c|l}
\hline \multicolumn{1}{c}{ Tahun } & \multicolumn{1}{c}{ Tema Kegiatan } \\
\hline $\mathbf{2 0 1 9}$ & $\begin{array}{l}\text { Pengembangan Agribisnis Porang Sebagai Alternatif Sumber Pangaan Lokal, } \\
\text { Mempertahankan Kelestarian Hutan dan Produk Unggulan di Desa Sambik Elen, Loloan } \\
\text { dan Senaru }\end{array}$ \\
\hline $\mathbf{2 0 2 0}$ & $\begin{array}{l}\text { Kajian Biofisik Lahan untuk Tanaman Porang Sebagai Anasir Konservasi pada Sistem } \\
\text { Agroforestri di Pulau Lombok (TAHAP USULAN) }\end{array}$ \\
\hline
\end{tabular}




\section{HASIL DAN PEMBAHASAN}

\section{Karakteristik Lokasi Penelitian}

\section{Bentuk Lahan, Kontur dan Ordo Tanah}

Lokasi percobaan terletak di Desa Desa Sambik Elen Kecamatan Bayan, Kabupaten Lombok Utara, Provinsi Nusa Tenggara Barat, dengan posisi geografis $\left(8^{\circ} 15^{\prime} 04.97^{\prime \prime} L S ; 116^{\circ}\right.$ 26'0.88" BT), dan tinggi dari permukaan laut (dpl) sekitar $450 \mathrm{~m}$. Landform di lokasi bervariasi mulai dari bergelombang sampai berbukit dengan tingkat kelerengan 15 sampai $25 \%$, dengan kondisi seperti ini berdampak pada laju aliran permukaan (run off) tinggi sehingga erosi pun sejalan dengan laju aliran permukaan.
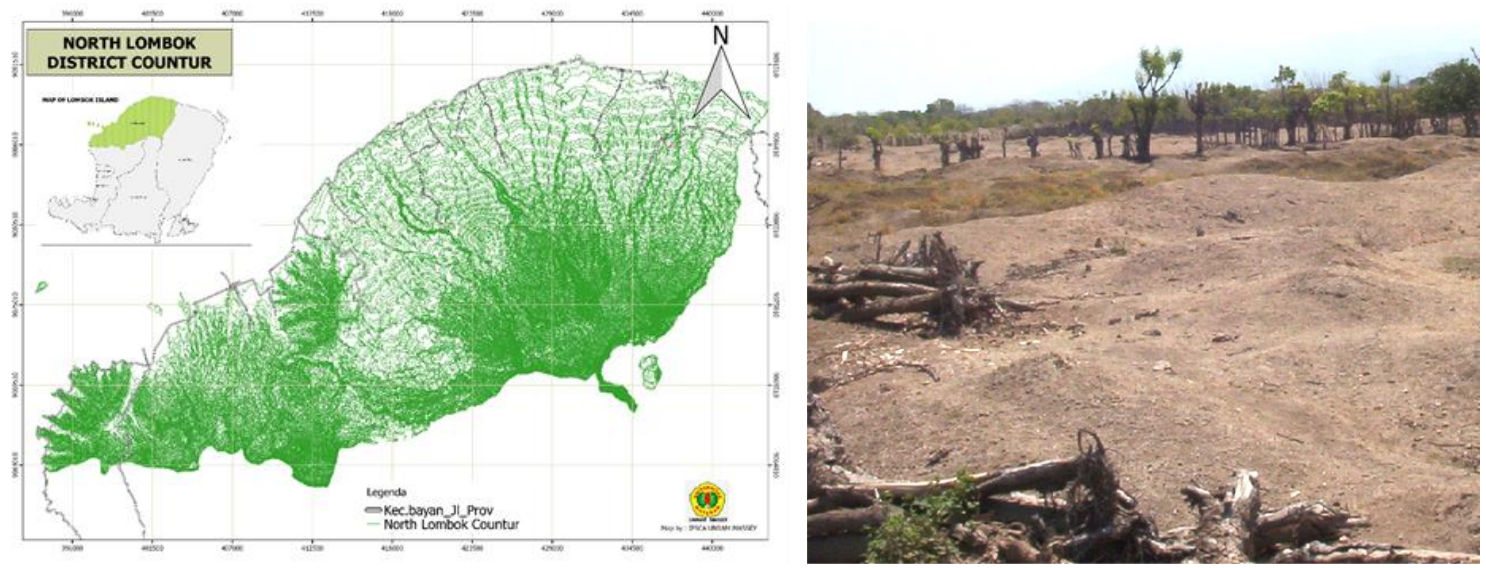

Gambar 1. Kontur Kab. Lombok Utara

Selain itu, partikel tanah disominasi oleh pasir dengan kandungan $45 \%$, kemudian disusul oleh partikel debu $38 \%$, serta partikel klei (clay) 17\%, sehingga kelas tekturnya tergolong loamy sand. Tanah tersebut memiliki kandungan bahan organik sangat rendah \%, sehingga mudah mengalami degradasi struktur tanah, yang berakhir pada rentan rehadap bahaya erosi.

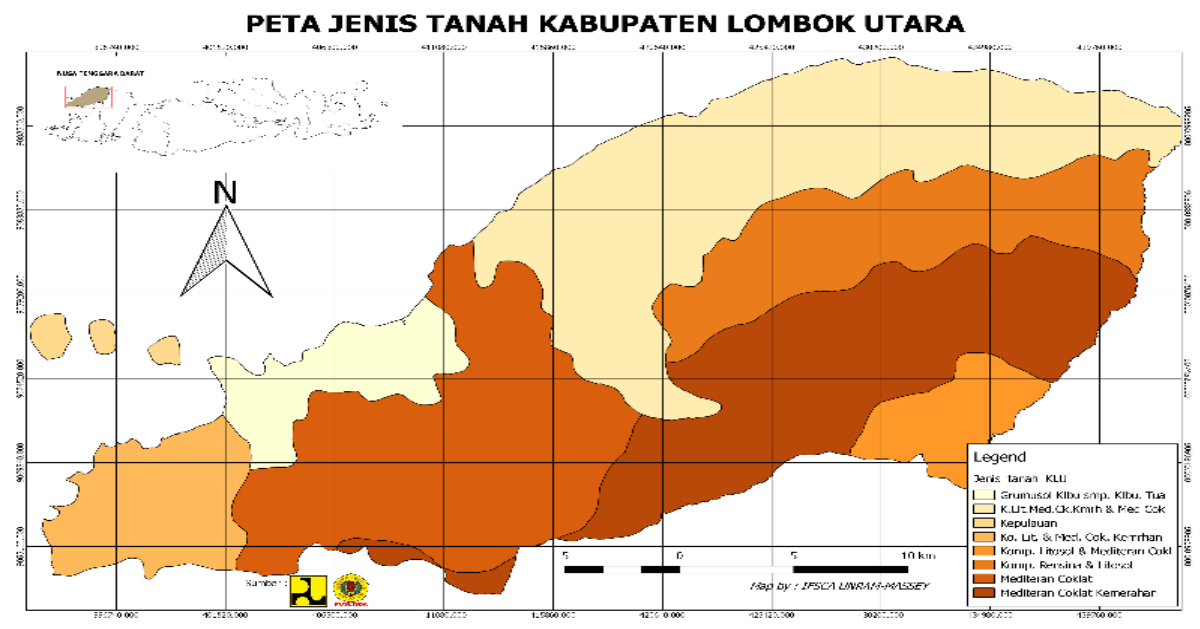

Gambar 2. Peta Jenis Tanah Kab. Lombok Utara 


\section{Kondisi Iklim}

Lokasi percobaan berada di dataran tinggi sekitar 468 di atas permukaan laut (dpl) dan merupakan Kawasan perkebunan (mente, kopi dan kakau), dengan kondisi iklim yang relative panas.

Hasil klasifikasi iklim didasarkan kepada jumlah kebutuhan air pada tanaman tahunan. Penyusunan tipe iklimnya berdasarkan jumlah bulan basah yang berlansung secara berturutturut diklasifikasikan menjadi lima zona iklim (Oldeman, 1980). Zona iklim merupakan pembagian dari banyaknya jumlah bulan basah berturut-turut yang terjadi dalam setahun. Sedangkan sub zona iklim merupakan banyaknya jumlah bulan kering berturut-turut dalam setahun. Pemberian nama Zone iklim berdasarkan huruf yaitu menjadi 5 tipe iklim yaitu:

- Iklim A. Iklim yang memiliki bulan basah lebih dari 9 kali berturut-turut

- Iklim B. Iklim yang memiliki bulan basah 7-9 kali berturut-turut

- Iklim C. Iklim yang memiliki bulan basah 5-6 kali berturut-turut

- Iklim D. Iklim yang memiliki bulan basah 3-4 kali berturut-turut

Berdasarkan urutan bulan basah dan kering dengan ketententuan tertentu diurutkan sebagai berikut:

a. Bulan basah bila curah hujan lebih dari $200 \mathrm{~mm}$

b. Bulan lembab bila curah hujan $100-200 \mathrm{~mm}$

c. Bulan kering bila curah hujan kurang dari $100 \mathrm{~mm}$

A. : Jika terdapat lebih dari 9 bulan basah berurutan

B. : Jika terdapat $7-9$ bulan basah berurutan

C. : Jika terdapat $5-6$ bulan basah berurutan

D. : Jika terdapat $3-4$ bulan basah berurutan

E. : Jika terdapat kurang dari 3 bulan basah berurutan

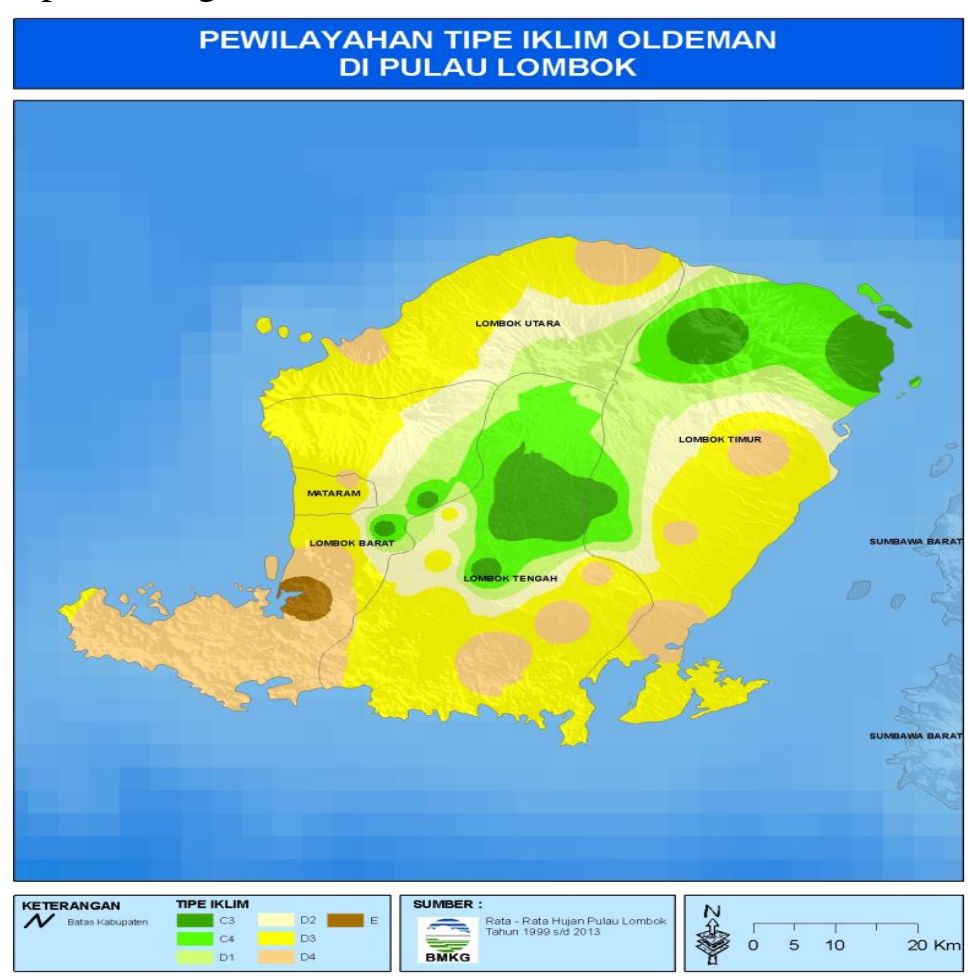

Gambar 3. Peta Klasifikasi Iklim Oldeman di Pulau Lombok 
Berdasarkan penjelasan di atas, lokasi tempat percobaan masuk dalam daerah semiarid, memiliki tipe iklim D4 (Gambar 4.3), dengan memiliki 7 bulan kering (curah hujan 120 mm per bulan) dan bulan basah berturut selama 3 bulan. Sedangkan curah hujan tahunan di kawasan pengambilan contoh tanah berkisar 1578 mm/tahun (BMKG, 2019). Kecuali di Desa Santong Kecamatan Gangga masuk ke dalam tipe iklim zona C4, dimana tingkat curah hujan $>100 \mathrm{~mm}$ perbulan dan $\mathrm{CH}$ tahunan berkisar > $1600 \mathrm{~mm} / \mathrm{tahun}$.

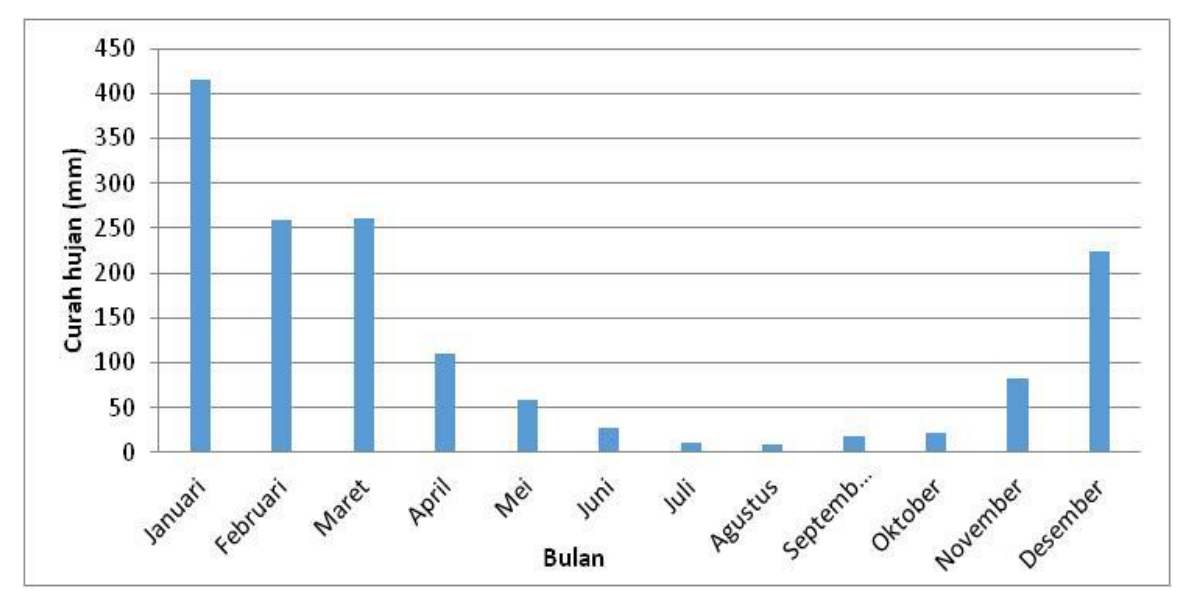

Gambar 4. CH bulanan di Kec. Bayan Tahun 2019

Ciri khas daerah dengan iklim semi-arid adalah perbedaan musim hujan dan kemarau yang sangat menyolok. Rata-rata hujan turun dalam tiga sampai empat bulan dan musim kemarau tujuh sampai delapan bulan. Curah hujan tahunan berkisar kurang dari $1000 \mathrm{~mm}$ di daerah tertentu sampai dengan $1200 \mathrm{~mm}$. Di dataran yang lebih tinggi, curah hujan bisa mencapai lebih dari 1500 sampai 2000 mm/tahun dengan lama musim hujan enam bulan. Evapotranspirasi jauh lebih besar daripada presipitasi. Ciri lain dari daerah semi-arid adalah intensitas hujan sangat tinggi pada musim hujan. Perbedaan antara musim hujan dan musim kemarau ini menyebabkan erosi yang sangat besar. (Roshetko dkk., 2000 dikutip Hairiah,K dkk., 2003).

\section{Karakteristik Fisik dan Kimia Tanah Indeks Kemantapan Agregat}

Ada dua lokasi sebagai pembanding dalam dalam melihat beberapa sifat fisik tanah, yakni sistem Agroforestri tanpa tanaman porang dan sistem agroporesty dengan tanaman porang. Dari hasil ananlisis laboratorium salah satu sifat fisik tanah yakni kemantapan agregat tanah menujukkan bahwa indeks kemantapan agregat tanah sistem Agroforestri dengan tanaman porang miliki indeks 58.8 sedangkan yang tanpa porang memiliki indeks 46.5 (Gambar 5) 


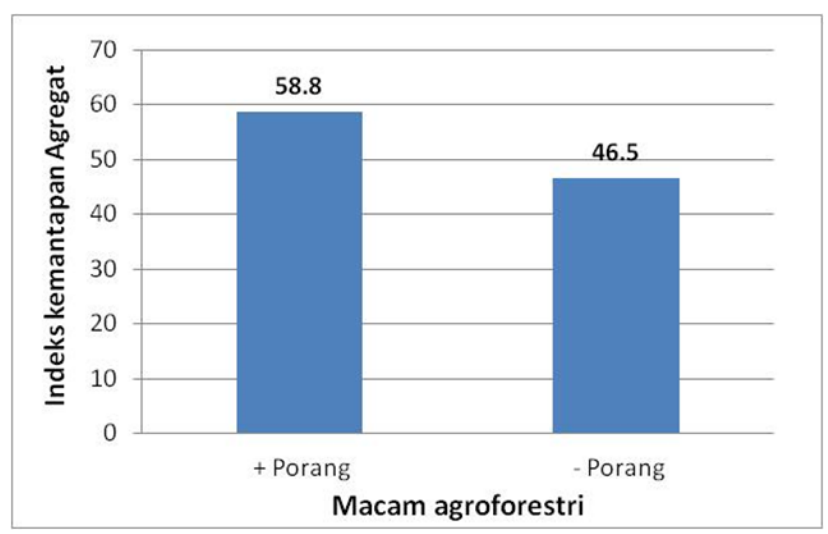

Gambar 5. Indek Kemantapan Agregat Sistem Agroforestri

Hal ini dikarenakan sistem Agroforestri dengan porang bisa mempertahankan kondisi lengas yang stabil dalam tanah sehingga daya rekat tanah menjadi lebih kuat dengan yang tanpa porang. Hampir seluruh bagaian tanaman porang (batang dan dauan) setelah fase generatif akan melapuk dan terurai pada tanah, sehingga berdampak pada penambahan bahan organic tanah dimana bahan organik mampu berperan sebagai bahan perekat yang akan terbentuknya agregat tanah dan yang memantapkan Agegat tanah. Bahan organik tanah adalah sebagai pengikat bahan seperti "semen" yang akan memantapkan Agregat tanah menjadi lebih stabil, inilah yang menyerap dan mempertahankan lengas tanah.

\section{Berat Volume (BV) dan Porositas Tanah}

Selain indeks kemantapan agregat tanah, berat volume dan porositas tanah juga menjadi Salah satu indicator sifat fisik tanah yang dikaji dalam penelitian ini. Hasil survei di lapangan menunjukkan bahwa berat volume menurun pada sistem Agroforestri dengan tanaman porang disebabkan oleh meningkatnya porositas total akbibat agregasi tanah yang lebih baik karena ada penambahan organic yang melapuk dan terurai dengan cepat dari sisa tanaman porang.
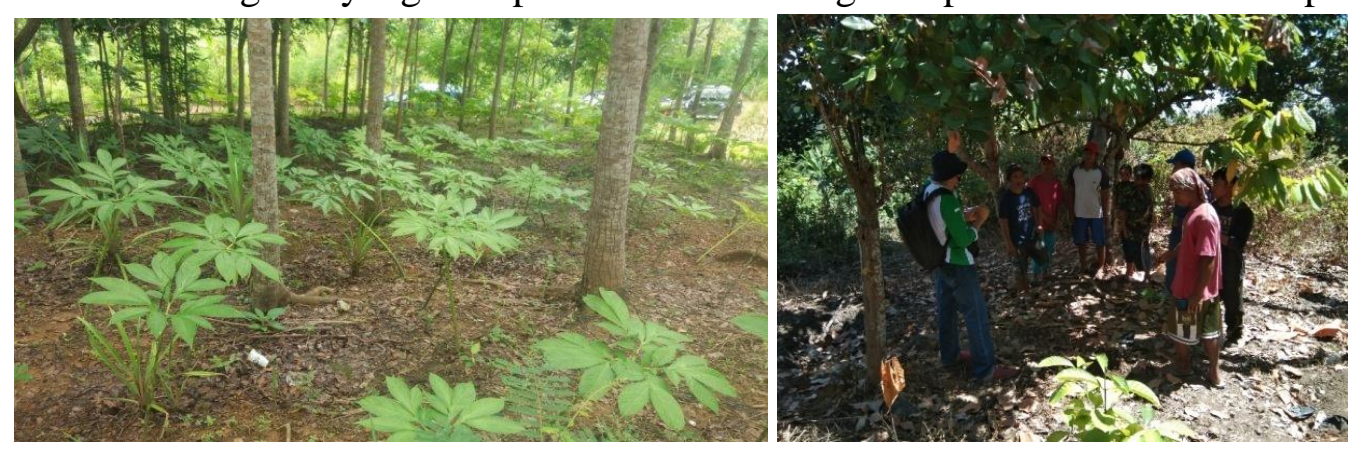

Gambar 6. Sistem Agroforestri + Tanaman Porang dan Sistem Agroforestri tanpa tanaman Porang

Sejalan dengan hasil survei lapangan, bahwa sistem Agroforestri dengan tanaman porang dibandingkan dengan Agroforestri tanpa tanaman porang menunjukkan hasil analisis laboratorium cukup berbeda nyata, dimana Agroforestri dengan tanaman porang menjukkan nilai $1,06 \mathrm{~g} / \mathrm{cm}^{3}$ sedangkan sistem Agroforestri tanpa porang menunjukkan nilai BV 1,10 $\mathrm{g} / \mathrm{cm}^{3}$. Sehingga dengan adanya tanaman porang pada sistem Agroforestri dapat menekan 
tingkat berat isi (BV) tanah pasiran di lokasi penelitian di Desa Sambik Elen Kec. Bayan Lombok Utara.
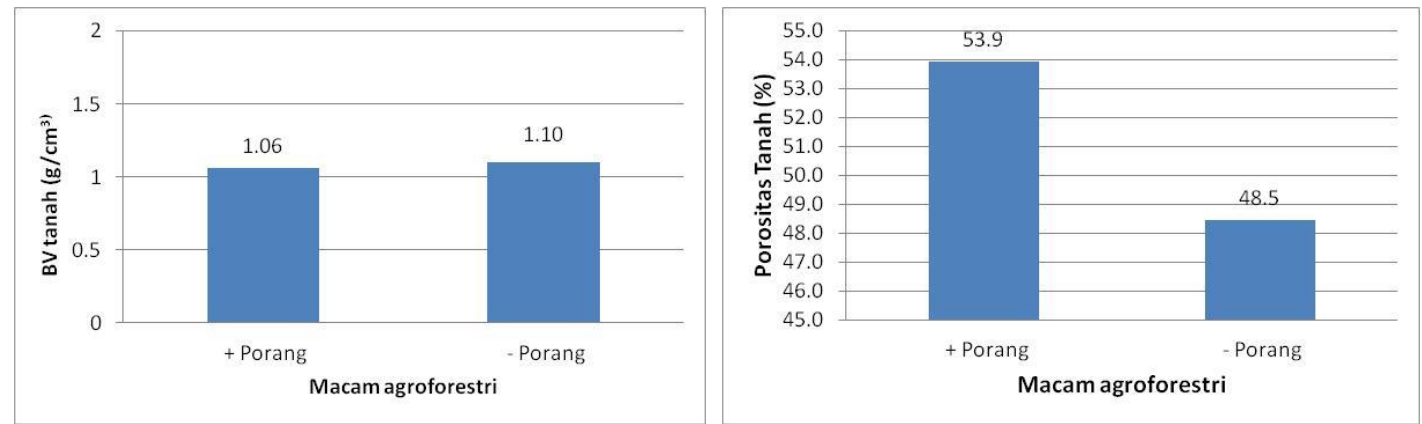

Gambar 7. Berat Volume (BV) dan Porositas Pada Sistem Agroforestri

Barzegar, Yousefi dan Daryashenas. (2002) melaporkan bahwa pemberian bahan organic berupa sersah tanaman berperan dalam memperbaiki porositas tanah pada lapisan olah $(0-20 \mathrm{~cm})$. Implikasinya adalah bahwa pupuk kendang berperan lebih besar dalam memperbaiki berat isi tanah (Baon et al., 2005).

Pengembalian residu atau sisa panen yang dikombinasikan dengan pupuk kandang, dapat memperbaiki kondisi fisik tanah seperti tingkat agregasi tanah menjadi baik, mengurangi tingkat kepadatan tanah dan porositas tanah menjadi baik.

Pemberian pupuk organik berpengaruh nyata $(\mathrm{p}<0,05)$ terhadap porositas total tanah. Secara umum porositas tanah pada lokasi pengamatan mulai dari $48,46 \%$ sampai $77,75 \%$ termasuk ke dalam kelas baik hingga porous Gambar 5.

\section{Hubungan Berat Volume (BV) Tanah dengan Porositas Tanah}

Hubungan berat volume (BV) dengan porositas tanah menunjukkan kecenderungan yang negatif yaitu semakin rendah berat isi tanah maka porositas tanah akan tinggi. Dengan pemberian bahan organic dapat menurunkan berat isi sebesar $103,9 \mathrm{~g} \mathrm{~cm}^{-3}$. Setiap $1 \%$ pemberian bahan organic berpengaruh terhadap penurunan BV tanah sebesar $46,8 \mathrm{~g} / \mathrm{cm}^{3}$. Model persamaan regresi linier ini cukup kuat untuk diterima karena mencakup 95\% pengaruh dari bahan organik terhadap berat volume tanah, sedangkan pengaruh eksternal lainnya $5 \%$.

Kepadatan tanah yang menurun akibat dari adanya bahan organik diikuti pula oleh turunnya nilai berat isi tanah dibandingkan dengan pemberian pupuk anorganik yang tidak memiliki masukan bahan organik tanah. Semakin meningkatnya berat isi tanah maka nilai porositas akan semakin menurun dan sebaliknya jika berat isi tanah menurun maka porositas tanah akan meningkat (Hillel, 1980).

\section{C-Organik Tanah}

Faktor penting yang sangat berpengaruh terhadap baik buruknya sifat tanah adalah kondisi bahan organic tanah. Dimana bahan organik merupakan komponen tanah yang penting dalam perbaikan dan peningkatan baik sifat fisik, sifat kimia maupun sifat biologi tanah. Menurut Goenadi (2006) terhadap sifat fisik tanah dapat meningkatkan stabilitas agregat tanah, menurunkan BV dan BJ serta menstabilkan permebilitas tanah, sehingga 
menciptakan struktur tanah yang mantap dan ideal bagi pertumbuhan tanaman yang berakibat pada tingkat porositas yang baik dan mengurangi tingkat kepadatan tanah serta mengurangi laju aliran permukaan (run off). Perbaikan fungsi bahan organik terhadap sifat kimia tanah adalah meningkatkan kapasitas tukar kation yang merupakan lokasi dan pusat hara sebelumdimanfaatkan oleh tanaman.

Penambahan bahan organic tanah berpengaruh terhadap kadar C-organik tanah. Hasil analisis laboratorium menunjukkan kadar C-organik dilokasi percobaan sistem Agroforestri dengan porang 1,98\% sedangkan pada sisitem Agroforestri tanpa porang 0,55\% (Gambar 8) tren ini menjukkan berbedanyata. Tingginya kandungan C-organik di sistem Agroforestri dengan tanaman porang dikarena adanya akumulasi tambahan sersah tanaman porang yang melapuk setuap tahunnya (tumbuh pada musim penghujan dan melapuk pada musim kemarau).

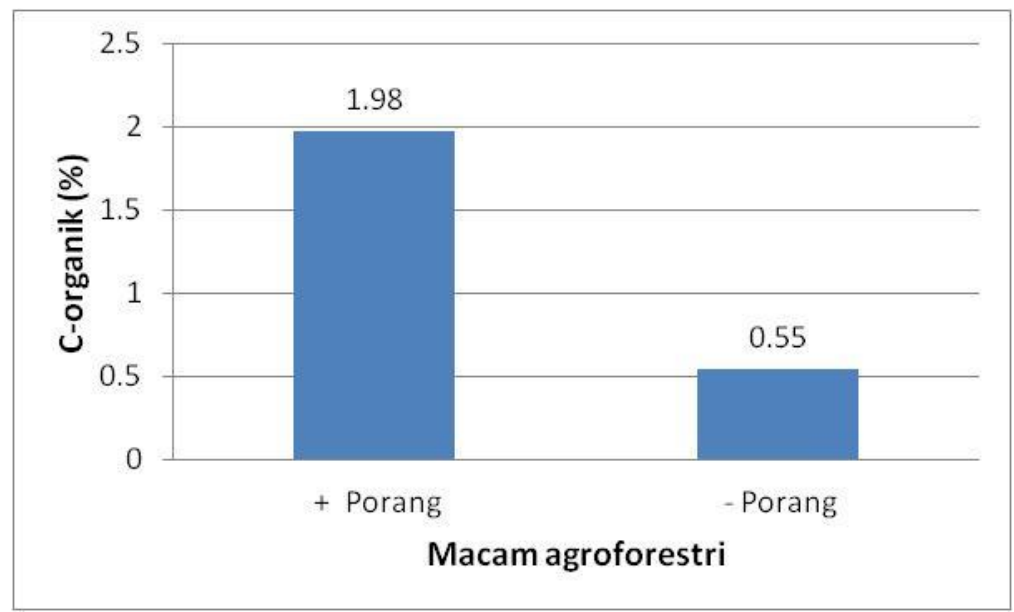

Gambar 8. Kadar C-organik pada Sisitem Agroforestri

Jadi, semakin banyak tanaman porang di bawah vegetasi tegakan, maka tingkat kandungan C-organik tanah akan meningkat pula. Demikian juga halnya dengan bahan organic (BO) tanah. Dengan adanya kandungan BO dalam tanah yang setabil juga mempertankan kehidupan mikro dan makro pauna dalam tanah.

Dengan demikian tanaman porang sangat cocok diintegrasikan dengan vegetasi tegakan baik yang ada di kebun warga maupun di kawsan hutan kemasyarakatan (HkM) maupun pda hutan produksi karena dapat dijadikan sebagai anasir konservasi pada sistem Agroforestri di Kab. Lombok Utara dan NTB pada umumnya.

Selain itu, nilai ekonomis tanaman porang yang sudah merambah pasar nasional dan internasional sehigga sangat potensial di kembangkan di Kawasan-kawasan peekebunan dan kehutanan seperti di Kab. Lombok Utara.

\section{KESIMPULAN}

Dari hasil kajian maka dapat ditarik kesimpulan bahwa, domistikasi porang memenuhi syarat sebagai tanaman non kayu pada sistem agroforestri, sebagai anasir konservasi tanah dan air pada tipologi lahan sub optimal di di kab. Lombok Utara dan Lombok pada umumnya. Rekomendasi yang dapat diberikan sebagai masukan dalam pengembangan tanaman porang pada lahan sub obtimal di Kab. Lombok Utara yakni, Penanaman porang 
agar tetap mengikuti azas konservasi, seperti bertanam searah kontur, dan Panen agar dilakukan secara bergilir pada hamparan lahan, menghindari pembongkaran yg berlebihan.

\section{Ucapan Terima Kasih}

Ucapan terimakasih diucapkan kepada Ketua Lembaga Penelitian dan Pengabdian (LPPM) Universitas Mataram, Dekan Fakultas Pertanian Universitas Mataram dan Ketua BP3F Fakultas Pertanian Universitas Mataram

\section{DATAR PUSTAKA}

Blake, G.R., 1986. Particle density. In A. Klute (Ed.), Methods of Soil Analysis (Part I). Agronomy 9. Soil Sci. Soc. Amer., Inc. Madison, USA.

Blake, G.R. and K.H. Hartge, 1986. Bulk density. In A. Klute (Ed.), Methods of Soil Analysis (Part I). Agronomy 9. Soil Sci. Soc. Amer., Inc. Madison, USA.

BMKG, 2019. Buletin Prakiraan Musim Hujan 2019/2020 Provinsi Nusa Tenggara Barat.Stasiun Klimatologi Lombok Barat. NTB.

Baon, J.B., Sukasih, R. dan Nurkholis. 2005. Laju dekomposisi dan kualitas kompos limbah padat kopi: pengaruh aktivator dan bahan baku kompos. Pelita Perkebunan 21, 31-42.

Barzegar, A.R., Yousefi, A. dan Daryashenas, A. 2002. The effect of addition of different amounts and types of organic materials on soil phsical properties and yield of wheat. Plant and Soil 247, 295-301.

Chenu, C., Y. Le Bissonnais, and D. Arrouays, 2000. Organic matter influence on clay wettability and soil aggregate stability. Soil Sci. Soc. Am. J., 64: 1479-1486.

FAO (Food and Agriculture Organization). 2015. Crop Water Information. Glosarry. Fao.org. available from http://www.fao.org.html [23 Feb. 2020].

Gee, G.W. and J.W. Bauder, 1986. Particle size analysis. In A. Klute (Ed.) Methods of Soil Analysis (Part I). Agronomy 9. Soil Sci. Soc. Amer., Inc. Madison, USA.

Goenadi, D.H. 2006. Pupuk dan Teknologi Pemupukan Berbasis Hayati. Dari Cawan Petri ke Lahan Petani. Yayasan John Hi-Tech. Idetama. Jakarta.

Hairiah, K.,M.A. Sarjono dan S. Sabarnurdin. 2003. Pengantar Agroforestri. ICRAF. Bogor

Hartanto, E.S., 1994. Iles-iles Tanaman Langka yang Laku Diekspor. Buletin Ekonomi.PT. Bank Pembangunan Indonesia (PERSERO), September-Oktober 19(5):21-25.

Heyne, K. (1987). Tumbuhan Berguna Indonesia (Terjemahan). Badan Litbang KehutananJakarta. Departemen Kehutanan, Jakarta.

Herlina, R. dan S Siburian, 2016. Sistim Agroforestri pada lahan bekas hutan sagu di kampung Baraway Kabupaten Kepulauan Yapen Papua. Prosiding Seminar Hasil Penelitian Kanoppi. (Optimalisasi Pengelolaan Hutan Berbasis Agroforestri untuk Mendukung Peningkatan Produktifitas Kayu dan HHBK, serta Pendapatan Petani). Cisarua Bogor https://www.researchgate.net/publication/331523137_Sistim_Agroforestri_pada_lahan _bekas_hutan_sagu_di_kampung_Baraway_Kabupaten_Kepulauan_Yapen_Papua [accessed Feb 19 2020]. 
Hermanto, D., S.R. Kamali, R. Kurnianingsih, dan N. Ismillayli, 2013. Optimalisasi Lahan Kering Kecamatan Bayan-Lombok Utara Menggunakan Asam Humat Terimmobil Dalam Rumput Laut Sebagai Pelengkap Pupuk Pada Tanaman Jagung (Zea Mays L)

Hidayat, R., F.D Dewanti, dan Hartojo. 2013. Tanaman porang karakter, manfaat dan budidaya. Graha ilmu. Yogjakarta.

Hillel, D. 1980. Fundamental of Soil Physics. Academic Press Inc. London.

Jansen, PCM., C. van der Wikl, dan W.L.A. Hetterscheid. Amorphophallus Blume ex Decaisne. In M. Flach and F. Rumawas (Eds), 1996. PROCEA: Plant Resources of Soth-East Asia No.9. Plant yielding non-seeds carbohydrates. Backhuys Publisher, Leiden. pp. 45-50.

Kertonegoro, B.D., S.H. Suparnawa, S. Notohadisuwarno, S. Handayani, 1998. Panduan Analisis Fisika Tanah. Laboratorium Fisika Tanah, Jurusan Tanah, Fakultas Pertanian Universitas Gajah Mada, Yogyakarta.

Kusnarta, I.G.M., B.D. Kertonegoro, B.H. Sunarminto, dan D. Indradewa, 2011. Beberapa Faktor yang berpengaruh Dominan terhadap Struktur Vertisol Tadah Hujan Lombok. Agroteksos Jurnal Ilmiah Ilmu Pertanian, Vol. 21, No. 2-3, pp:120-128.

Lahiya, A.A., 1993. Budidaya Tanaman Iles-iles dan Penerapannya untuk Sasaran Konsumsi serta Industri. Seri Himpunan Peninggalan Penulisan Yang Berserakan. Terjemahan J.V. Scheer, GHWD Dekker, and E.R.E. Helewijn. 1937/1938/1940. De Fabrikasi Van Iles-Iles mannaanmee uit Amorphophallusknolle en enigetoepassingmogelijkheden Bergcultures). Bandung.

Lase, E. 2007. Budidaya Umbi Hutan (Porang). Biro Pembinaan dan Konservasi SDH Perhutani. Jawa Timur. http://www.smallcrab.com/ Mengenal-tanamanporang [19 Feb. 2020].

Nelson, D.W. and L.E. Sommers, 1982. In Klute (Ed.), Methods of Soil Analysis (Part II). Agronomy 9. Soil Sci. Soc. Amer., Inc. Madison, USA.

Oldeman, L. I. (1980). The Agroclimatic Maps of Kalimantan, Maluku, Irian Jaya and Bali, West and East Nusa Tenggara. Bogor: Contributions No. 60, Central Research Institute for Agriculture, $32 \mathrm{p}$.

Priyono, J., I Yasin, Dahlan, dan Bustan, 2019. Identifikasi Sifat, Ciri, dan Jenis Tanah Utama di Pulau Lombok. Jurnal Sains Teknologi \& Lingkungan Vol.5,No.1. pp:19-24

Rofik, K., R. Setiahadi, I. R. Puspitawati, M. Lukito, 2017. Potensi Produksi Tanaman Porang (Amorphophallus muelleri Blume) di Kelompok Tani MPSDH Wono Lestari Desa Padas, Kecamatan Dagangan, Kabupaten Madiun. Agri-tek: Jurnal Ilmu Pertanian, Kehutanan dan Agroteknologi. Vol.17 No.2, pp. 1411-5336.

Rosman, R. dan S. Rusli, 1991. Tanaman Iles-iles. Edisi khusus Littro. VII (2): 17-21.

Sumarwoto, 2011. Budidaya Iles-iles (Amorphophallus muelleri Blume). Di Bawah Tegakan Tanaman Hutan. Workshop Pengembangan Agroforestri dalam Mendukung Ketahanan Pangan dan Kesehatan Masyarakat. Program I-MHERE B.2.c. KP4, UGM. Yogyakarta.

Suprayogo, H., D.K. Hairiah, N. Wijayanto, Sunaryo, dan M. Noordwijk, 2003. Peran Agroforestri pada Skala Plot: Analisis Komponen Agroforestri sebagai Kunci 
Keberhasilan atau Kegagalan Pemanfaatan Lahan Indonesia. World Agroforestri Centre (ICRAF), Southeast Asia Regional Office. P0 Box 161 Bogor.

Vuksan, V., J.L. Sievenpiper, R. Owen, J.A. Swilley, P. Spadafora, D.J. Jenkins, E. Vidgen, Brighenti, R.G. Josse, L.A. Leiter, Z. Xu, and R. Novokmet, 2000. Benefecial effects of viscous dietary fiber from konjuc-mannan in subjects with the insulin resistance syndrome: results of a controlled metabolic trial. Diabetes Care, Jan. 23(1): 9-14.

Wuddivira, M.N., R.J. Stone and E.I. Ekwue, 2008. Clay Organic Matter and Wetting Effect on Splsh Detachment and Aggregate Breakdown under Inense Rainfall. Soil Sci. Scoc. A. J., 73, 226-232. 